International Review of Research in Open and Distributed Learning Volume 20, Number 1

February - 2019

\title{
Examining the Complexities of Parental Engagement at an Online Charter High School: A Narrative Analysis Approach
}

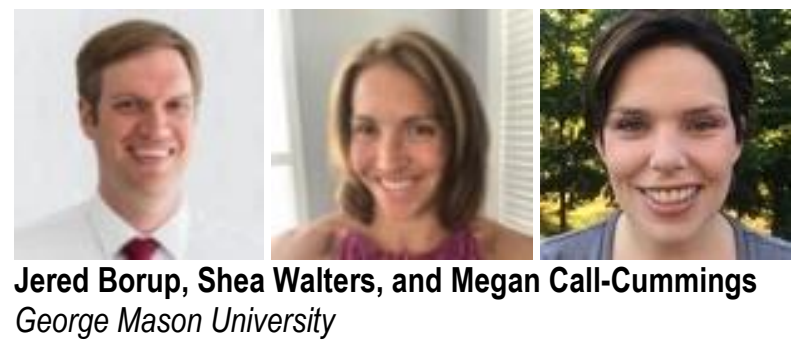

\begin{abstract}
With the rapid growth of K-12 online learning opportunities, calls have come for more and better parental engagement to improve student engagement and reduce student attrition. In this article, we drew from a larger study to share rich narratives from three parents of students who required high levels of parental support for their online learning while enrolled at a charter cyber school. In the first narrative, a mother describes her experiences attempting to work with her son Ivan, who rejected her efforts and disobeyed rules while enrolled in the cyber school. The move from a brick-and-mortar school to the cyber school further strained their relationship and the mother was unprepared to manage Ivan's learning. The second narrative focuses on how a mother attempted to support Matthew, who lacked self-regulation abilities. The mother who previously homeschooled Matthew, turned to the cyber school because she wanted "less on [her] shoulders" but underestimated the amount of support Matthew required and became frustrated at her lack of control over the pace and content of courses. The final narrative focuses on a mother who had two students enrolled in the cyber school. Each student exhibited different needs that required her to adapt the support strategies she used with Hannah, who procrastinated, and Karl, who lacked confidence. These narratives highlight some of the complexities parents navigate when engaging with their children's online learning.
\end{abstract}

Keyword: parent engagement, narrative analysis, charter cyber school, homeschooling 


\section{Introduction}

$\mathrm{K}-12$ online enrollments have grown rapidly and perceptions of online learning are also becoming more positive (Johnson, Adams Becker, Estrada, \& Freeman, 2015) despite higher attrition rates in online courses than in face-to-face courses (Freidhoff, 2017). Research and frameworks used to examine online learning in higher education can offer some insights (see Bawa, 2016) but these findings should not be generalized to K-12 settings due to differences between the student populations and the types of support they require. Parental engagement is one example of a critical type of support universally recognized by the K-12 community but largely ignored when examining adult student populations.

Research conducted in brick-and-mortar schools indicates that when students' parents are involved, they are more likely to succeed (Wilder, 2014). Parents can have an even greater impact on their children's online learning than in traditional courses, especially when students take most or all of their courses online (Liu, Black, Algina, Cavanaugh, \& Dawson, 2010). However, little research has examined parents' responsibilities. Identifying and defining types of parental engagement in non-traditional environments may help us increase and leverage the types of parental engagement that are most likely to impact student engagement and learning.

Because parental engagement in their children's online learning has been under-researched, qualitative research examining the experiences of parents and the obstacles they encounter is necessary to understanding their experiences and perceptions (Hasler-Waters, Borup, \& Menchaca, 2018). What little qualitative research has been done in this area examines themes drawn from surveys, interviews, and observations with many parents. These articles have offered important insights but have failed to provide rich descriptions of individual parents' experiences. Wolcott (1994), who claimed to have never studied more than one of anything, identified "a tendency to increase the scale, rather than the depth, whenever the question of sample size is raised among qualitative researchers" (p. 181). Following Wolcott's guidance, we examined three parents' experiences and perceptions in an attempt to highlight the complexities they navigated when engaging with their children's online learning.

\section{Literature Review}

\section{Trends in Online Learning}

While most students use online learning to supplement their face-to-face coursework, cyber schools (fulltime online programs) are one of the fastest growing forms of online learning (Gemin, Pape, Vashaw, \& Watson, 2015). Survey research has helped to identify reasons that parents enroll their children in cyber schools. Based on a national survey of online course providers, Gemin et al. (2015) found 20\% of cyber school students came from homeschooled populations who sought a high school diploma, desired more social interactions, and/or required support their parents were unable to provide. Using student $(\mathrm{n}=269)$ 
and parent ( $\mathrm{n}=232$ ) surveys, Beck, Maranto, and Shakeel (2016) found parents of rural students enrolled in cyber schools accessed more educational opportunities for their students. Beck, Egalite, and Maranto (2014) found that parents enrolled their children with special needs in cyber schools so they could be more involved in their children's learning. Harvey, Greer, Basham, and Hu's (2014) analysis of 140 student surveys found students were drawn to online courses for the flexibility to pursue extracurricular opportunities (Harvey et al., 2014). Cyber schools also provide alternative educational opportunities for students with prolonged health issues or who feel unsafe or uncomfortable at school (Fernandez, Ferdig, Thompson, Schottke, \& Black, 2016).

One important downside of online courses is higher attrition rates than in face-to-face courses. For instance, Freidhoff (2017) examined 453,570 online course enrollments from 90,878 students and found online course pass rates (58\%) were lower than the pass rates for those same students in face-to-face courses (78\%). Early reports comparing online and face-to-face performance found no significant difference (Cavanaugh, 2001; Cavanaugh, Gillan, Kromrey, Hess, \& Blomeyer, 2004; Ferdig, DiPietro, \& Papanastasiou, 2005). However, these reports relied on small sample sizes and unequal comparison groups (Barbour, 2013). More recent reports have addressed these limitations and provided a clearer understanding of student performance in cyber schools. Woodworth et al. (2015) conducted the largest study on student performance at cyber schools, comparing student data from 158 charter cyber schools face-to-face students who were similar demographically. The comparison found that "online charter students have much weaker growth overall" (p. 23).

\section{Parental Engagement}

Because parents' engagement in their children's online courses is not well studied, researchers have sought insights from parental engagement frameworks established in face-to-face settings such as those from Epstein (1987) and Hoover-Dempsey and Sandler (2005). However, researchers have found the Epstein's (1987) and Hoover-Dempsey and Sandler's (2005) frameworks helpful but ultimately incompleteespecially when attempting to identify the specific types of parental engagement.

Epstein's (1987) framework was developed following the analysis of surveys from 1,200 parents and 3,700 elementary school teachers and principals in face-to-face elementary schools. The analysis identified four primary types of parental involvement: providing for students' basic physiological and academic needs, participating in school-to-home communication, volunteering in school and extracurricular events, and assisting students at home to develop academic and social skills. Guided by Epstein's framework, Curtis (2013) interviewed eight cyber school parents and identified three types of parental engagement that appeared to be especially impactful on students' performance: motivating, monitoring, and mentoring efforts. Burdette and Greer (2014) lightly based their research on Epstein's framework when they administered a survey to a stratified sample of parents across the United States with children with disabilities enrolled in an online course. Over half of their 119 parent participants indicated that they helped their child to understand course assignments and content, encouraged them to complete assignments, organized their time, and helped them to develop positive social and behavioral skills. 
Rather than focus on the specific activities like Epstein's framework, Hoover-Dempsey and Sandler's (2005) framework identified four broad mechanisms of influence that could occur at home or school: encouraging, modeling, reinforcing, and instructing. In a case study involving 14 teachers, parents, and administrators at a full-time elementary cyber school, Hasler Waters and Leong (2014) built on Hoover-Dempsey and Sandler's (2005) framework and found that parents impacted their children's learning by organizing their time and space, setting expectations, motivating, monitoring, and guiding their learning. Using a survey developed by Hoover-Dempsey and Sandler (2005), Liu et al. (2010) created and validated an instrument that measured parents' encouraging, modeling, reinforcing, and instructional efforts in online courses.

To encourage a more coordinated and focused research agenda, Borup, West, Graham, and Davies (2014) drew on face-to-face and online parental engagement research to create the Adolescent Community of Engagement (ACE) framework, which identified and defined specific types of parental engagement in their children's online learning. Borup and colleagues then conducted two case studies at a cyber school to refine and expand the types of parental engagement originally identified in the ACE framework (Borup, 2016; Borup, Stevens, \& Hasler Waters, 2015). The following forms of engagement were consistently identified by charter cyber school teachers, students, and parents:

- Instructing: Parents provided instructional support by answering content-related questions when possible, reviewing assignment directions and projects, and helping students develop study skills.

- Organizing: Parents provided students with an organized learning space and schedule.

- Nurturing relationships and interactions: Parents worked to maintain caring relationships with students and facilitated interactions between students and their online teachers.

- Monitoring and motivating: Parents closely monitored student performance and motivated students as needed.

\section{Parents' Reasons for and Obstacles to Involvement}

Hoover-Dempsey and Sandler (2005) identified seven contributors to a parent's decision to engage in their children's face-to-face learning: perceived roles constructed throughout their lives, self-efficacy, selfperceived knowledge and skills, self-perceived available time and energy, general school invitations, teacher actionable invitations, and student invitations. Based on their framework, we predict that parents' inexperience with being or supporting an online student will impact how they perceive their roles and the self-efficacy, knowledge, and skills that are required to successfully engage in their children's online learning. A national survey also found online schools can differ in their perceptions of parental engagement (Woodworth et al., 2015). Qualitative researchers have found that parents increase their engagement activities when they recognize online students' underperformance (Curtis, 2013; Hasler Waters, 2012). Parents' tendencies to increase their engagement following underperformance may help to explain why 
correlational research has not identified stronger relationships between the amount of parental engagement and students' overall performance (Black, 2009; Borup, Graham, \& Davies, 2013).

\section{Methods}

\section{Context and Data Collection}

We conducted our research at Mountain Cyber Charter (MCC), a charter cyber high school. MCC employed 21 teachers. Of their 338 students, $90 \%$ were white, $18 \%$ had previously been homeschooled, and 14\% were economically disadvantaged. All parents were automatically made members of MCC's parent organization. Parents and students also attended a mandatory face-to-face orientation in which MCC provided students with a computer and established expectations for students and parents.

Based on teacher recommendations, we identified 10 students with varying levels of engagement and support needs. We invited the parent most involved in each student's learning to participate in two onehour interviews, using a semi-structured interview protocol created from the ACE framework. Because two of the identified students were siblings, we conducted three interviews with their parent. In total, we conducted 19 hour-long interviews with nine parents.

\section{Analysis}

Guided by elements of constant comparison coding methods (Glaser, 1965), we analyzed all 19 parent interviews, the results of which we reported in an earlier article (see Borup, Stevens, \& Hasler Waters, 2015). In this article, our aim is to provide richer descriptions of the experiences of the three parents who described the most complex obstacles to supporting their students. As the parent of the set of siblings, one of the parents participated in three interviews. The other two parents participated in two hour-long interviews each for a total of seven interviews.

We used a narrative inquiry approach to offer a nuanced description of the three parents' experiences as well as to provide an uninterrupted opportunity for these parents to "speak" for themselves. We recognize that narrative inquiry is a broad field and the methods used in narrative inquiry are diverse:

The term narrative carries many meanings and is used in a variety of ways by different disciplines, often synonymously with story...the narrative scholar [pays] analytic attention to how the facts got assembled that way. For whom was this story constructed, how was it made and for what purpose? What cultural discourses does it draw on-take for granted? What does it accomplish? (Riessman \& Speedy, 2007, p. 428-429) 
Our goal was to, as much as possible, elicit and present the experiences of these parents in a way they themselves might present them to another parent or friend. Prompted by Riessman and Speedy's (2007) comments, we recognize that these parents' experiences were constructed for research purposes; participants knew they were being recorded and also knew their words would likely be published for others' consumption and, perhaps, scrutiny. Therefore, we understand some personal, embarrassing, or otherwise negative details might not have been shared. However, we feel it is still important to share these narratives because they give the research community, practitioners, and other parents access to the nuances and subtleties of the learning these parents have gleaned from their experiences. We therefore seek to present these parents' "knowledge from the past and not necessarily knowledge about the past" (Bochner, 2007, p. 203).

To present the nuances and subtleties of this "knowledge from the past," we turned to Polkinghorne (1995), who presented two types of narrative inquiry: analysis of narrative and narrative analysis; the former is deconstructive and the latter is constructive. Here we have chosen to conduct a variation of Polkinghorne's (1995) constructive narrative analysis approach so that we could present the uninterrupted, rich, and reconstructed narratives of three parents' experiences with online schooling in their own words-an approach that we previously followed (Borup, West, \& Graham, 2013). Our ultimate goal was to preserve and honor the voices of those who are closest to and strongest experts of their own lived experiences, while creating opportunities for others to learn from those experiences. Therefore, we reconstructed these parents' experiences with online schooling, using their own words as much as possible and inserting bracketing filler words only to connect ideas and ensure the flow of the storied experience. We also engaged in multiple rounds of peer debriefing to ensure our reconstruction reflected as closely as possible the intent of the informant. After reconstruction, we examined each story holistically and identified key lessons about how parents can best support their children in online schooling environments.

\section{Findings}

In this section, we share the results from the narrative analyses. To protect participants' identities, we refer to them using pseudonyms. In the first narrative, a parent describes her experiences attempting to work with her son Ivan, who rejected her efforts and disobeyed rules. The second narrative focuses on how a parent attempted to support Matthew, who lacked self-regulation abilities. The final narrative focuses on a parent who used different strategies to support each of her two children: Hannah, who procrastinated, and Karl, who lacked confidence.

\section{Supporting Ivan}

I graduated with a teaching certificate in elementary education. I never used [my degree] except with my own kids because I did homeschool with my children-we adopted the last two, including Ivan. [At the time,] I put Ivan on the first-grade [online] program with [a large online course provider] where he learned 
English really well. Our family moved and I put him in the [brick-and-mortar school] and they took him at grade five, so he skipped the fourth grade. He did okay in grade five-a lot of $\mathrm{B}$ and $\mathrm{C}$ work. Then he wanted to go back to [the large online course provider] for sixth grade.

He started getting madder and madder [at home in the online program] and throwing books and ripping papers up. I put him in public school [for eighth grade]. He did okay, he got a 3.o [G.P.A.] for the year. At the high school there were so many Fs. [Ivan was] very influenced by outside influences. The art teacher said [Ivan and] his friends would make fun of the teacher or make fun of kids. He wouldn't come home after [school]. He would hang out with "friends," skip classes, that kind of stuff. I thought, "Okay, this is not going to continue." I happened to read a magazine that mentioned [MCC]. I thought, "I will try that."

Everything started off great last fall [at MCC], grade-wise and everything. I can access the parent login [and] see how many hours and minutes were spent in each subject each day. I checked grades today and there are two classes that are being passed right now out of six. Two of them that he is failing he might make it past $60 \%$. I would be really surprised [if he passed] the other two.

My suggestions are rejected. "We could do flashcards. Why don't you contact [your teacher] and get some help?" He doesn't want it, "No, I can do it myself, I don't need you." I see how much time [he] spent here and how much time [he] spent there, "I looked and noticed you hadn't spent the 30 minutes on math that you said you did." I get a, "How dare you?! How dare you check on me?!" I can look ahead and say, "Okay, I see you have something due this day." And he'll say, "None of your business, I'll get it in, why are you bugging me?!” Initially when we started I would check on grades and say "Why aren't you doing well?” [He'd reply], "You don't know what you are talking about, this is my school, not yours." My husband is really good at math and has tried to help, but [Ivan] says, "You don't know how to teach." He will sometimes try to bully me into doing [his assignments] but we say no.

We set up a desk [in the living room] and he's never taken [the school-provided computer] into his bedroom. [MCC administrators] have supposedly blocked as much as they can [on his computer]. That was great until he discovered YouTube. So now there are hours and hours spent on that-continually. Time to time, I will check from behind, "Are you doing homework?” [He'll reply], "Oh, I'm taking a break right now.” That's just a justification.

He also loves sleep. He can sleep until 1:30 [p.m.] if I don't drag him out. Other times I have to threaten, "You won't get a shower because the water will be cold because I'll be doing the wash when you wake up." He eats breakfast with the family and he is invited to go get dressed, sit at the computer, but normally he goes right back to bed.

It's also [Ivan's] attitude. You hear all the time with him, "Why should I learn this, this is boring?" We can say, "Grades are the most important thing. Do well in school and then we could afford your insurance." or "This has to be done before this fun thing can happen. Now you get this done. You're free when your little brother comes home." He does it anyway. "I'm taking off, goodbye." I just physically can’t restrain [him]. 
I don't know how to change that attitude. It's not your normal situation. Most of the time, I don't want to go in there and actually find out what is going on because then it's like, "Well, you didn't tell me to do it. It's your fault. You didn't push me to do it, it's your fault.” He pushes me around. That's why I'm just staying away from it. I don't know what else to do so I have to leave it up to him. I have run out of options.

[MCC] needs a school for the mother. Other than an orientation, I have only interacted with a few [teachers]. [Teachers] send progress reports once a week. We have received phone calls from time to time, not very often. It's a two-way street. The exciting thing about [MCC] was that they had access to the teachers pretty much anytime they wanted. I can call an individual teacher, but I don't. I would like individual parentteacher time every other week. I'm guessing that there are others like [Ivan]. There needs to be something more done. I wish I didn't have a [child] who was needing that much. [We are] just doing our best.

\section{Supporting Matthew}

I have four kids [and Matthew] is the last-he just turned 15. We have homeschooled the past eighteen years. My husband and I wanted to have our values instilled in them [and] we love doing life-learning things together. I loved everything about [homeschooling but] I [was] getting a little tired after all those years and I wanted less on my shoulders. I was happy for [MCC] to come along for Matthew.

$[\mathrm{MCC}]$ was a huge learning curve. I realized at the beginning, "Wow! He needs much more help here than I ever thought." It was grueling. I had to sit side by side with him for the first 4-6 weeks to help. We would start at 9:00 in the morning and do everything [together]. We wanted to pull our hair out. The whole goal [of enrolling in MCC] was to make it so I didn't have to be side by side with him. I also didn't have the time to keep up with that. At some point, I needed to let him sail with it. Then at a slow rate, I was backing up and encouraging him and telling him that he needs to take over [and] contact his teachers. He wasn't keeping up with the content per each week's deadline.

He can definitely improve on time management. At the beginning, I didn't know how to help organize his week. He likes to work late and sleep in. [We] could use help with some type of scheduling. That's the hardest part. [I've] written out [a learning schedule] and he's like, "I know. I know. But then I always get interrupted or sidetracked." He loves to invent. [Next to his school] desk he has a whole workbench where he will be creating or soldering. So just the other day, he goes, "We need to rearrange my room. The workshop stuff is making it over to the school desk." That took him almost a year to figure out that, "Gee, this isn't a good setup.” I don't know if I would have noticed that so I'm trying to let him figure it out.

He likes a little more flexibility and one day he might be on [the computer] for three hours and take the rest of the day off. The beauty of homeschool is you can be flexible. There is no time [with MCC] to do any life things that we were used to doing, "Hey do you want to go to the library?" or "Let's go to the zoo." [He says,] "Nope, we can't. I have to do some work.” It's just like, “Aw, come on.” Less time is spent with each other [doing] good, valuable life-teaching events. And then again, it could be the time management part. We feel 
rushed. It's like, “Oh that's nice that you want to talk about that but we don't have time because your deadline is at 9:00 p.m. Let's get this done.” It's hard.

I'm trying to not hover over him and let him try to figure how to be successful with his time management. [I] don't want to be controlling. I want him to own it. There's that fine line. Basically, I have said, "I'm here. Let me know if you need any help." I used to look at his grades and assignments every day or every other day. [Now I check grades] maybe once a week. Now that he's failing a couple classes, I will look at some things and see where he needs help. Mostly I just make sure that he is on time on the current week and keeping things turned in. I tell him every day, "Let me know if you need any help. Is there anything I can help you with?” And he will say, “No, no, no I'm fine.” And then later I will see something that maybe didn't get turned in. He just needs to finish and finish strong.

\section{Supporting Hannah and Karl}

I have five children and work full-time outside of the home. I didn't go to college because college just wasn't my thing. Before [MCC] we did homeschooling. Karl and Hannah were both in [Mountain Cyber Charter] together, and now my younger two are both going to go.

Hannah was getting bullied a lot [at the brick-and-mortar school]. Her self-esteem was horrible so we pulled [her] out. It was pulling teeth to get her to do her schoolwork [with the homeschool curriculum]. Now, the last few years that she's been in [MCC], she's had no problem. She would get the laptop out every morning, do her schoolwork, and then she would have the weekend to do her fun stuff. She's a very good student. I think her grade point average is 3.6 something.

Hannah is just a procrastinator. It takes me nudging, pushing her a lot. But when I do, she does it. Once she figured out how much free time she had to herself if she just sat down and did it, she was all over it. When it comes to the deadline, she gets nervous. "Oh my gosh! I only have two weeks left." I'm like, "Yeah, you had two months. I don't know what to tell you. I guess you better hurry.” And she'll [get it done] every time.

She needs help with [organizing her time]. Sometimes if she was falling behind then I would try to help her, "So maybe do the quicker stuff first and the harder stuff last, or vice versa." Last semester we sat down together and she read her 6-8 page paper to me. I just have to kind of help her, "Okay, well it would probably fit better here, and not here." We did stuff like that together. I watch her grades, and every day, we go through what she's done and what she has left. I think listening is a lot and checking up and making sure she's doing okay.

[Karl] went to a brick-and-mortar school until fourth grade and then we pulled him out [and homeschooled him]. He is a fun kid. He helps around the house a lot. He totally hates school [but] loves to work. He's just really a motivated kid. He just wants to be done so badly that he does school on the weekends even. I don't know why he's always had such a problem with school. He doesn't like anybody telling him what to do and so he's going to fight you tooth and nail. 
He's a very needy child. For some reason, he doesn't have the confidence in himself to just go and do it. He hates instruction, but if he doesn't get instruction every step of the way, he gets lost and confused and he won't even try. Math is his worst subject ever. Karl comes to us every day. "Do it for me." Me and my husband have to be very careful how much we help. He'll act like he has no clue, until you finally get so frustrated and irritated with him that you give him the answer. It's gotten to the point where we just will give him the basics and if he still doesn't get it, "Okay, then contact your teacher."

Public school, they're like, “Okay, mom, I didn't get this. Can you help me with this?” [MCC] is nothing like that because they go directly to their teachers. If they have any struggle whatsoever, teachers are always there. I feel more my role with him is making him go to the teacher. "Dude, you've got to go to the teachers because I don't know." I don't know why he doesn't like going to the teachers for help, I guess because they won't do it for him.

He likes to know that he's done a good job. Like yesterday, "Hey, I've got four assignments in math today. I'm going to break-that's all I have left Mom. I'm going [to turn in] two of them on Thursday and two of them on Friday." Then he'll just randomly call me in the middle of the week, "Hey mom, guess what? I have a $98 \%$ in history, I have a $79 \%$ in math."

Hannah's a procrastinator, but Hannah also knew she had to do it, and she knew what to do. She never had low self-esteem when it came to school. [Karl's] needy so I try and help him without giving him the answers. Hannah wants someone to discuss it with. Karl wants you to tell him step for step for step what exactly he needs to do. I'll help as much as I can. They know we're here if they need us. If [online students] don't have somebody to come and talk to, what are they going to do, where are they going to go?

\section{Discussion}

In this section, we synthesize these parents' "knowledge from the past" (Bochner, 2007, p. 203) and connect them to research findings, offering implications for practice and research. We do this for each of the three narratives separately in an effort to preserve the uniqueness of each parent's experiences and insights.

\section{Ivan}

Supporting Ivan proved especially difficult for his mother even though she had previously earned her teaching certificate. Over the years, she struggled to find an educational fit for Ivan. Ivan was homeschooled for two different stretches and enrolled in a brick-and-mortar school before enrolling at MCC. At times these decisions followed defiant outbursts from Ivan. For instance, he was enrolled in a brick-and-mortar school because when he was learning from home "he started getting madder and madder and throwing books and ripping papers up." However, Ivan's misbehavior only continued in the brick-and-mortar setting. His mother attributed it to his "friends," which prompted her to enroll him in MCC to remove negative "outside influences." Similarly, Beck et al. (2016) found that parents commonly enrolled students in a cyber 
school following behavior problems. However, while enrolled in a cyber school, Ivan continued to demonstrate misbehavior and anger towards his mother. Ivan's mother believed that she had "run out of options" and made the decision to "leave it up to [Ivan]" to improve his performance. Hoover-Dempsey and Sandler (2005) found that parents were more likely to engage in their students' learning when they received invitations from their student. The reverse was true in Ivan's situation: Ivan's mother stopped engaging in his learning when he rejected her efforts.

In face-to-face settings, Levin at al. (1997) found that when homework raised student-parent tension it proved counter-productive to students' performance and well-being. Similarly, McNeal (2012) explained that in some cases parent involvement can harm their relationships with their children. If parent-student relationships are already strained when the student is learning in a brick-and-mortar school setting, then a shift to cyber schooling will likely worsen that relationship. However, when students are being homeschooled, a shift to a cyber school may help to reduce tensions because many of the instructional responsibilities shift away from the parent to the online teacher.

Online teachers commonly highlight that they enjoy no longer having to deal with misbehavior in the classroom (Larkin, Brantley-Dias, \& Lokey-Vega, 2015). However, cyber school programs should recognize that student misbehavior is still occurring at home and being addressed by a parent who may not be prepared to do so. As a result, some parents require support from the online program. As Ivan's mother stated, there "needs to be a school for the mother." A cyber school psychologist may have helped to avoid academic and behavioral problems (Tysinger, Tysinger, \& Diamanduros, 2016). However, this type of support is both under-researched and underused in cyber school settings (Tysinger et al., 2016). Additional research should seek to identify strategies for supporting defiant students directly through the use of school psychologists and other professionals as well as strategies for supporting parents.

\section{Matthew}

Matthew's mother, who homeschooled Matthew since first grade, enrolled him at MCC because she wanted "less on [her] shoulders." She was surprised at how much support Matthew still required: "He needs much more help here than I ever thought." She "didn't have the resources" to fully support him and began "telling him that he needs to take over." When that occurred, Matthew's performance suffered due to poor selfregulation, which is commonly cited as a contributing factor to online learning's high attrition rates. Roblyer, Freeman, Stabler, and Schneidmiller (2007) explain: "Student ability to handle distance education courses appears to depend more on motivation, self-direction, or the ability to take responsibility for individual learning" (p. 11) than on their ability to learn the course content. Because of their physical proximity, the responsibility for helping students develop self-regulation skills often falls on parents. Matthew's mother struggled to support him in the development of those skills. She admitted, "as a parent I did not know how to help organize his week" and her efforts to create a learning schedule were commonly rejected by Matthew. 
Matthew's mother believed the learning schedule was too demanding and missed having "all the time in the world" for spontaneous "live-learning things" when she homeschooled. Like Matthew's mother, other homeschooling parents may also be drawn to online learning to lessen their responsibilities while not fully understanding how the change will remove some control and flexibility. In contrast, parents with students in brick-and-mortar schools will likely find that cyber schooling provides them with more flexibility. Borup's (2016) case study examining cyber school teacher perceptions explained that, "teachers found that those [parents] who previously homeschooled their students needed to be 'willing to step back' and those whose students previously attended brick-and-mortar schools needed to be willing to take a step forward" (p. 79). As a result, online programs should recognize these differences and customize their orientation and support materials accordingly. Additional research is needed to better understand how parents' previous background impacts how they engage in their students' online learning.

\section{Hannah and Karl}

Unlike Ivan and Matthew, Hannah and Karl accepted and sought their mother's support. Their needs varied and their mother had to adjust her efforts accordingly. Hannah habitually procrastinated but was able to complete the work, and Karl liked to work ahead but would stop working when he encountered challenges. This affirms previous assertions that the types and levels of parental engagement depend on the attributes and abilities of each student (Hasler Waters et al., 2018). Hannah and Karl's mother's ability to impact their learning appeared to be the result of their trusting relationships. As Borup, Stevens, and Hasler Waters (2015) discussed, "[Parents'] trusting relationships with their students formed the foundation for all other types of parental engagement" (para. 23). As a result, parent-student relationships should be considered when deciding whether online learning is best for students. As Rose, Smith, Johnson, and Glick (2015) stated, "Rather than 'Is online learning right for me?' students should be asked, 'What support systems do you need to be successful in online learning?” (p. 75). Students should also be asked, "Would you be willing to accept support if offered?”

\section{Conclusion}

Drawing on research in face-to-face settings, researchers and policymakers have called for an increase in parental engagement in online schooling. In this study, we sought to understand the nuances and complexities of individual parents' attempts to support their children's learning in a cyber school setting. Examining the reconstructive narratives of three parents' experiences has allowed us to illustrate that complexity and simultaneously to show the breadth of parent experiences. These narratives lead us to the conclusion that many factors should be considered when parents make decisions about their students' education and the ways that they choose to support them once those decisions have been made. Our analysis suggests that parents need to take into account their children's learning preferences and their relationship with them when deciding to enroll them in an online program, because it is the parent who will be primarily 
responsible for encouraging and supporting engagement in online schoolwork if their child lacks internal motivation. Parents should also consider just how much time high-level support of online learning will take and how much control they will have over their children's learning.

While the primary purpose of this research was not to identify themes across narratives, we did recognize some commonalities. First, taken together, the narratives demonstrate that the support that parents provide needs to be tailored to their children based on their attributes, skills, and behavior. While parents were often reactive to students' behavior, their close relationships with their children and understanding their children's attributes and skills allowed them to be more proactive in their engagement. Second, students' lack of self-regulation made it difficult to maintain the level of consistent engagement that is required to be successful in a cyber school. Third, parents were unprepared to provide the levels and types of supports that their children required, even when they recognized their needs. Lastly, our analysis highlights how important it is for students to be willing to accept support from their parents and how difficult it can be for parents to fulfill their responsibilities when their child is resistant to their efforts.

While the nature of qualitative research prevents generalizations to other settings, these narratives may provide insights to school administrators, teachers, parents, and researchers. Additional case studies may help practitioners to not only develop a better understanding of the obstacles that parents face when engaging with their children's online learning, but also develop empathy for those parents. While research has examined teachers' empathy for parents in face-to-face settings (Broomhead, 2013) and teachers' ability to recognize their online students' social presence (Hawkins, Barbour, \& Graham, 2011), we are not aware of any research that has examined online teachers' empathy for parents or online teachers' ability to recognize parents' social presence in mediated communication. Additional case studies should also be conducted examining parental engagement in a variety of cyber school settings. Previous case studies have focused on understanding parents' behaviors and perceptions, but more research should consider students' perspectives, especially given the crucial role that acceptance of parental support played for students in our study. These efforts may provide insights into the invitations that students extend to parents, which can have an important impact on parents' engagement (Hoover-Dempsey \& Sandler, 2005). These qualitative efforts can provide important insights to those interested in designing large-scale quantitative research. For instance, researchers should look to develop and validate instruments that measure different types of parent engagement that could help to identify the impact on or correlations with learning outcomes. 


\section{References}

Barbour, M. K. (2013). The landscape of K-12 online learning: Examining what is known. In M. G. Moore (Ed.), Handbook of distance education (3rd ed., pp. 574-593). New York: Routledge.

Bawa, P. (2016). Retention in online courses: Exploring issues and solutions-a literature review. SAGE Open. https://doi.org/10.1177/2158244015621777

Beck, D., Egalite, A., \& Maranto, R. (2014). Why they choose and how it goes: Comparing special education and general education cyber student perceptions. Computers \& Education, 76, 70-79. https://doi.org/10.1016/j.compedu.2014.03.011

Beck, D., Maranto, R., \& Shakeel, M. D. (2016). Does rural differ? Comparing parent and student reasons for choosing cyber schooling. The Rural Educator, 37(3).

Black, E. W. (2009). An evaluation of familial involvements' influence on student achievement in K-12 virtual schooling (Doctoral dissertation). University of Florida, Gainesville, FL.

Bochner, A.P. (2007). Notes toward an ethics of memory in autoethnographic inquiry. In N. K. Denzin \& M. D. Giardina (Eds.), Ethical futures in qualitative research: Decolonizing the politics of knowledge (pp. 197-208), New York: Routledge.

Borup, J. (2016). Teacher perceptions of parent engagement at a cyber high school. Journal of Research on Technology in Education, 48(2), 67-83. https://doi.org/10.1080/15391523.2016.1146560

Borup, J., Graham, C. R., \& Davies, R. S. (2013). The nature of parental interactions in an online charter school. American Journal of Distance Education, 27(1), 40-55. https://doi.org/10.1080/08923647.2013.754271

Borup, J., Stevens, M. A., \& Hasler Waters, L. (2015). Parent and student perceptions of parent engagement at a cyber charter high school. Online Learning, 19(5). https://doi.org/10.1017/CBO9781107415324.004

Borup, J., West, R. E., \& Graham, C. R. (2013). The influence of asynchronous video communication on learner social presence: A narrative analysis of four cases. Distance Education, 34(1), 48-63. https://doi.org/10.1080/01587919.2013.770427

Borup, J., West, R. E., Graham, C. R., \& Davies, R. S. (2014). The adolescent community of engagement: A framework for research on adolescent online learning. Journal of Technology and Teacher Education, 22(1), 107-129. 
Broomhead, K. E. (2013). 'You cannot learn this from a book'; Pre-service teachers developing empathy towards parents of children with Special Educational Needs (SEN) via parent stories. European Journal of Special Needs Education, 28(2), 173-186. https://doi.org/10.1080/08856257.2013.778109

Burdette, P. J., \& Greer, D. L. (2014). Online learning and students with disabilities: Parent perspectives. Journal of Interactive Online Learning, 13(2), 67-87.

Cavanaugh, C. (2001). The effectiveness of interactive distance education technologies in K-12 learning: A meta-analysis. International Journal of Educational Telecommunications, 7(1), 73-88. Retrieved from https://www.learntechlib.org/p/8461/

Cavanaugh, C., Gillan, K. J., Kromrey, J., Hess, M., \& Blomeyer, R. (2004). The effects of distance education on K-12 student outcomes: A meta-analysis. Naperville, Illinois: Learning Point Associates. Retrieved from https://eric.ed.gov/?id=ED489533

Curtis, H. (2013). A mixed methods study investigating parental involvement and student success in high school online education (Doctoral dissertation). Northwest Nazarene University, Nampa, ID.

Epstein, J. L. (1987). Parent involvement: What research says to administrators. Education and Urban Society, 19(2), 119-136. https://doi.org/10.1177/0013124587019002002

Ferdig, R. E., DiPietro, M., \& Papanastasiou, E. (2005). Teaching and learning in collaborative virtual high schools. Naperville, Illinois: Learning Point Associates.

Fernandez, H., Ferdig, R. E., Thompson, L. A., Schottke, K., \& Black, E. W. (2016). Students with special health care needs in K-12 virtual schools. Educational Technology \& Society, 19(1), 67-75.

Freidhoff, J. R. (2017). Michigan's virtual learning effectiveness report 2015-16. Lansing, MI: Michigan Virtual University. Retrieved from http://media.mivu.org/institute/pdf/er 2016.pdf

Gemin, B., Pape, L., Vashaw, L., \& Watson, J. (2015). Keeping pace with K-12 digital learning: An annual review of policy and practice (12th ed.). Durango, CO: Evergreen Education Group. Retrieved from https://www.inacol.org/resource/keeping-pace-with-k-12-digital-learning-12th-edition/

Glaser, B. G. (1965). The constant comparative method of qualitative analysis. Social Problems, 12(4), 436-445. Retrieved from http://www.jstor.org/stable/798843

Harvey, D., Greer, D., Basham, J., \& Hu, B. (2014). From the student perspective: Experiences of middle and high school students in online learning. American Journal of Distance Education, 28(1), 1426. 
Hasler Waters, L. (2012). Exploring the experiences of learning coaches in a cyber charter school: A qualitative case study (Doctoral dissertation). University of Hawaii, Honolulu, HI.

Hasler-Waters, L., Borup, J., \& Menchaca, D. M. P. (2018). Parental involvement in K-12 online and blended learning. In K. Kennedy \& R. Ferdig (Eds.), Handbook of research on K-12 online and blended learning (2nd ed.; pp. 403-422). ETC Press. Retrieved from http://press.etc.cmu.edu/index.php/product/handbook-of-research-on-k-12-and-blendinglearning-second-edition/

Hasler Waters, L., \& Leong, P. (2014). Who is teaching? New roles for teachers and parents in cyber charter schools. Journal of Technology and Teacher Education, 22(1), 33-56.

Hawkins, A., Barbour, M. K., \& Graham, C. R. (2011). Strictly business: Teacher perceptions of interaction in virtual schooling. The Journal of Distance Education, 25(2).

Hoover-Dempsey, K. V., \& Sandler, H. M. (2005). Final performance report for OERI grant \#R305T010673: The social context of parental involvement: A path to enhanced achievement. Nashville, TN: Vanderbilt University. Retrieved from https://ir.vanderbilt.edu//handle/1803/7595?show=full

Johnson, L., Adams Becker, S., Estrada, V., \& Freeman, A. (2015). NMC horizon report: 2015 K-12 edition. Austin, TX: The New Media Consortium. Retrieved from http://cdn.nmc.org/media/2015-nmc-horizon-report-k12-EN.pdf

Larkin, I. M., Brantley-Dias, L., \& Lokey-Vega, A. (2015). Job satisfaction, organizational commitment, and turnover intention of online teachers in the K-12 setting. Online Learning, 2O(3), 26-52.

Levin, I., Levy-Shiff, R., Appelbaum-Peled, T., Katz, I., Komar, M., \& Meiran, N. (1997). Antecedents and consequences of maternal involvement in children's homework: A longitudinal analysis. Journal of Applied Developmental Psychology, 18(2), 207-227. https://doi.org/10.1016/So1933973(97)90036-8

Liu, F., Black, E., Algina, J., Cavanaugh, C., \& Dawson, K. (2010). The validation of one parental involvement measurement in virtual schooling. Journal of Interactive Online Learning, 9(2), $105^{-132 .}$

McNeal, R. B. (2012). Checking in or checking out? Investigating the parent involvement reactive hypothesis. The Journal of Educational Research, 105(2), 79-89.

https://doi.org/10.1080/00220671.2010.519410 
Polkinghorne, D. E. (1995). Narrative configuration in qualitative analysis. International Journal of Qualitative Studies in Education, 8(1), 5-23.

Riessman, C.K. \& Speedy, J. (2007). Narrative inquiry in the psychotherapy professions. In D. J. Clandinin (Ed.), Handbook of narrative inquiry: Mapping a methodology (pp. 426-456). Thousand Oaks, CA: Sage Publications.

Roblyer, M. D., Freeman, J., Stabler, M., \& Schneidmiller, J. (2007). External evaluation of the Alabama ACCESS initiative phase 3 report. Eugene, OR: International Society for Technology in Education.

Rose, R. M., Smith, A., Johnson, K., \& Glick, D. (2015). Ensuring equitable access in online and blended learning. In T. Clark \& M. K. Barbour (Eds.), Online, blended, and distance education in schools: Building successful programs (pp. 71-83). Sterling, VA: Stylus Publishing.

Tysinger, D., Tysinger, J. A., \& Diamanduros, T. D. (2016). Crisis events in K-12 online learning: Educator perceptions and preparedness. National Youth-At-Risk Journal, 2(1), 41-48.

Wilder, S. (2014). Effects of parental involvement on academic achievement: A meta-synthesis. Educational Review, 66(3), 377-397.

Wolcott, H. F. (1994). Transformative qualitative data: Description, analysis, and interpretation. Thousand Oaks, CA: Sage Publications.

Woodworth, J. L., Raymond, M. E., Chirbas, K., Gonzalez, M., Negassi, Y., Snow, W., \& Van Donge, C. (2015). Online charter school study. Stanford, CA: Center for Research on Education Outcomes. Retrieved from https://credo.stanford.edu/pdfs/OnlineCharterStudyFinal2015.pdf

\section{Athabasca University}

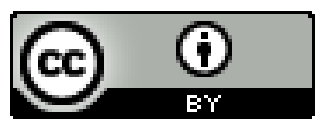

